\title{
Inovações Tecnológicas em Escolas Públicas: Análise de Fatores Motivadores
}

\author{
Nayanne Soares ${ }^{1}$, Carlos Almeida ${ }^{1}$, Juliana Saraiva ${ }^{1}$ \\ ${ }^{1}$ Departamento de Ciências Exatas - Universidade Federal da Paraíba (UFPB) \\ Rua da Mangueira, s/n, - Companhia de Tecidos Rio Tinto \\ CEP 58297-000 - Rio Tinto - PB - Brasil \\ \{nayanne.soares, cviniro, julianajags \}@dce.ufpb.br
}

\begin{abstract}
This paper proposes to investigate factors driving high schools teachers in two public schools to use the technological resources (hardware and software). This research also draws a parallel with the Human Needs Theory proposed by Maslow. The research method used was semi-structured interviews, performed with 11 teachers. Qualitative analysis used NVivo for helping the identification of motivations and resistance of technology adoption. The school infrastructure problems were mentioned as the greatest demotivation. On the other hand, the personal growth, and the interest for increasing the student learning were found as motivation factors.
\end{abstract}

Resumo. Este artigo propõe investigar fatores que impulsionam professores de Ensino Médio em duas escolas estaduais da Rede Pública a utilizarem os recursos tecnológicos (hardware e software). Esta pesquisa também faz um paralelo com a Teoria das Necessidades Humanas de Maslow. O método de pesquisa utilizado foi entrevista semi-estruturada, realizada com 11 professores. A análise qualitativa utilizou o NVivo para auxiliar na identificação das motivações e resistências em usar tecnologias. Os problemas de infraestrutura da escola foram mencionados como os maiores indícios de desmotivação na adoção de TIC. Por outro lado, o crescimento pessoal e a busca por aumento no rendimento do aluno foram encontrados como fatores motivadores.

\section{Introdução}

A figura da escola/professor, que lida diariamente com alunos 'nativos digitais' - passam parte da vida conectados em um mundo interativo e cercado por computadores, videogames, tabletes e smartphones - [Fróes 2016] precisam acometer a um devido comprometimento, planejamento e inserção desses recursos tecnológicos, que é visto no âmbito educacional. Dispositivos tecnológicos podem ser utilizados como uma ferramenta potencialmente facilitadora-mediadora no processo de ensino-aprendizagem.

Entretanto, a adoção de Tecnologias da Informação e Comunicação (TICs) em escolas da rede pública de ensino pode ser dificultada ou mesmo anulada por uma série de fatores estruturais, contextuais e até mesmo motivacionais da equipe onde a tecnologia está sendo inserida. Para Dantas (2016), "um professor excluído digitalmente terá menos possibilidade de articulação e argumentação no mundo virtual, e, por conseguinte, suas práticas pouco contemplarão as dinâmicas". Sabendo que essas iniciativas podem influenciar na adoção de TICs por parte dos professores, buscou-se analisar quais fatores 
V Congresso Brasileiro de Informática na Educação (CBIE 2016)

Anais do XXII Workshop de Informática na Escola (WIE 2016)

podem ser considerados motivacionais ou de resistências para a adoção de tecnologias. É importante esclarecer que o termo "Tecnologias da informação" está inserido neste trabalho dentro de um contexto mais amplo como sendo qualquer hardware, software ou mesmo sistema de infraestrutura tecnológica de rede que seja usado para melhorar a execução das atividades diárias do usuário.

Neste sentido, foi feita uma pesquisa de campo e se buscou fazer um paralelo da Teoria de Motivação ou Teoria da Hierarquia das Necessidades Humanas (Maslow 1943), até hoje estudada, com o comportamento dos professores de escolas públicas. Essa teoria foi desenvolvida por Abraham H. Maslow e teve como foco principal encaminhar o homem para um crescimento rumo à sua autorrealização, considerada o ápice da realização das necessidades humanas. "As necessidades se tornam mais sofisticadas à medida em que mudamos de nível." [Mendes, 2014]. Assim, à medida em que a menor necessidade é satisfeita, surgem novas necessidades, elevando os patamares até chegar ao ultimo nível de satisfação que é o da autorrealização. O ciclo dinâmico das necessidades foi classificado pelas seguintes necessidades: as fisiológicas, de segurança, as sociais, de estima e de autorrealização como é possível ser vista na Figura 1.

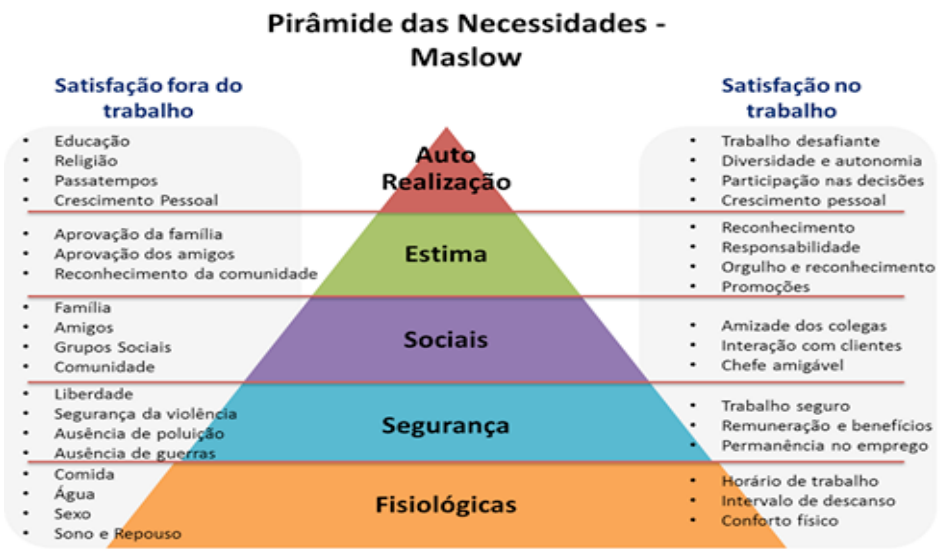

Figura 1. Pirâmide das Necessidades de Maslow [Maslow 1943]

Considerando o cenário descrito anteriormente, este artigo visa investigar os fatores motivadores ou de resistências que levam os professores a adotar (ou não) as tecnologias de informação (hardware e software) disponíveis nas escolas. Assim, as seguintes Questões de Pesquisa (QP) foram levantadas:

- (QP01) Como são exploradas pedagogicamente as tecnologias de informação (hardware e software) nas escolas?

- (QP02) Quais são as motivações dos professores para a utilização dos recursos tecnológicos disponíveis na escola?

- (QP03) Se houver resistência, quais os motivos da resistência na adoção de recursos tecnológicos disponíveis na escola?

Sendo assim, o objetivo geral da pesquisa é investigar os fatores motivacionais para adoção das tecnologias da informação (hardware e software) em escolas públicas. Para atingir este objetivo, os seguintes objetivos específicos foram estipulados: (i) listar as 
V Congresso Brasileiro de Informática na Educação (CBIE 2016)

Anais do XXII Workshop de Informática na Escola (WIE 2016)

motivações e desmotivações dos professores, para a utilização das inovações tecnológicas; (ii) relacionar as práticas pedagógicas utilizadas com os fatores motivacionais; (iii) identificar as aplicações das teorias dos conceitos de motivação aos professores frente à inserção da tecnologia da informação na educação. $O$ artigo se organiza da seguinte maneira: Seção 2 expõe a metodologia de pesquisa e na Seção 3, os resultados da pesquisa são detalhados. Por fim, a Seção 4 apresenta as considerações finais.

\section{Metodologia}

Esta seção descreve a metodologia utilizada neste trabalho considerada de carácter qualitativa pois segundo Graupmann (2014), "A pesquisa qualitativa pressupõe que a produção do conhecimento sobre os fenômenos humanos e sociais tem como foco compreender e interpretar seus conteúdos do que apenas descrevê-los.". Assim, se faz necessário abranger percepções em relação aos fatores motivacionais e/ou possíveis resistências dos professores quanto ao uso das tecnologias da informação (hardware e software) possibilitando a exploração mais detalhada do objeto observado (professores expostos as tecnologias da informação).

\subsection{Passos Metodológicos}

Os passos metodológicos definidos nessa pesquisa fora: (i) estudo bibliográfico, (ii) desenvolvimento do protocolo de pesquisa, (iii) execução de piloto, (iv) convite às escolas, (v) execução das entrevistas, (vi) transcrição e (vii) análise dos dados. A execução da pesquisa inicialmente foi caracterizada por um levantamento das teorias motivacionais e técnicas de execução de entrevistas. Em seguida o protocolo de pesquisa que foi desenvolvido e refinado. Finalizado o protocolo, um piloto foi executado onde professores do curso de Licenciatura em Ciência da Computação (LCC) que tiveram experiência/vivência com inserção de TIC em meios educacionais foram entrevistados. Isso tornou possível fazer ajustes no protocolo a ser aplicado quando as escolas fossem abordadas. Além disso, a execução do piloto balizou e ajustou as perguntas, além de dar mais noção do tempo necessário para realização das entrevistas e propiciar direcionamento as entrevistas de forma objetiva.

Em paralelo à execução do piloto, foram levantados os dados junto à Secretaria de Educação do Estado sobre escolas que se caracterizavam como potenciais sujeitos da pesquisa. Elas foram escolhidas por terem implantado na escola algum recurso tecnológico utilizado no processo ensino-aprendizagem. É importante ressaltar que o termo 'recurso tecnológico' está sendo usado como qualquer hardware ou software que promova a efetiva utilização da tecnologia da informação nas tarefas diárias de seus usuários. Assim, exemplos de recursos tecnológicos podem ser mencionados como datashow, computador, programas de computador, tablets, objetos de aprendizagem, dentre outros. Após essa seleção das potenciais escolas, um convite aos professores foi feito pessoalmente na escola, onde foi apresentado o objetivo da pesquisa em andamento e explicado quais seriam os potenciais sujeitos a serem entrevistados. Além disso, um termo de confidencialidade e sigilo foi entregue à direção da escola a fim de garantir que nenhuma informação privada 
V Congresso Brasileiro de Informática na Educação (CBIE 2016)

Anais do XXII Workshop de Informática na Escola (WIE 2016)

ou comprometedora seria revelada por nenhum pesquisador. Por fim, uma carta convite foi apresentada buscando agendar a entrevista com os professores das escolas. Foram entregues convites a 05 escolas estaduais, no entanto, 02 escolas se dispuseram colaborar. Após a realização das entrevistas nas escolas que aceitaram participar da pesquisa, elas foram transcritas e analisadas. Essas etapas serão descritas mais detalhadamente nas seções a seguir.

\subsection{Instrumento de Coleta}

O instrumento de coleta utilizado nesta pesquisa foi a aplicação de uma entrevista semi-estruturada baseada num questionário contendo 19 perguntas. O questionário foi dividido em três etapas: (i) A caracterização do entrevistado, (ii) identificação dos recursos tecnológicos e (iii) levantamento das motivações/possíveis resistências para adoção de TIC. É importante ressaltar que todas as perguntas da (iii) parte do questionário estão correlacionadas com as caraterísticas motivacionais no âmbito do trabalho descrita pela Teoria das Necessidades Humanas desenvolvida por Maslow (1943). Por questão de espaço elas não estão apresentadas aqui, mas podem ser conferidas no site da pesquisa ${ }^{1}$. Por fim, é importante ressaltar que o protocolo ${ }^{2}$ da pesquisa também não foi inserido neste texto por questões de espaço.

\subsection{Transcrição e Análise de Dados}

Após a realização das entrevistas os dados foram transcritos para planilhas do Microsoft Excel. Em seguida, essas transcrições serviram como fonte de dados para serem analisadas com auxílio do software $\mathrm{NVivo}^{3}$ - software de análise qualitativa utilizado na pesquisa. Com a ajuda desse software foi possível organizar e analisar as informações. O NVivo além de facilitar a análise qualitativa dos dados, sejam eles dados textuais ou audiovisuais, automatiza a análise de diálogos, questões abertas e textos diversos.

Existem conceitos que são importantes serem destacados para compreender o funcionalmente do NVivo": fonte, nó e codificação. A fonte abriga o que foi importado da planilha armazenando todos os dados da transcrição do diálogo das entrevistas gravadas em áudio. O nó abriga todos os trechos correspondentes à identificação do discurso e a codificação é a associação dos diálogos das fontes em cada nó. No total foram criados 17 nós vinculados ao nó 'raiz' da pesquisa 'MotivaçãoAdotarTIC'.

Para esta pesquisa, os seguintes nós foram criados: 'AdotarRecursoPorNecessidade', 'AdotarRecursoPorSugestao', 'AdotarRecursoPorMotivacao'. Esses 3 nós foram criados com o intuito de especificar nos discursos de onde parte o estímulo para utilização dos recursos tecnológicos na escola por

\footnotetext{
${ }^{1}$ https://goo.gl/xwfxCl

2 https://goo.gl/ky30ua

${ }^{3}$ http://www.qsrinternational.com/
} 
V Congresso Brasileiro de Informática na Educação (CBIE 2016)

Anais do XXII Workshop de Informática na Escola (WIE 2016)

parte dos professores. Adicionalmente, os nós 'IncentivoUsoTIC' e 'NãoIncentivoUsoTIC' buscam saber através dos discursos se na escola há meios de incentivo que possam levar o aumento da motivação dos professores a usarem TIC. Já os nós 'FormaçãoContinuadaTIC' e 'NenhumaCapacitaçãoTIC', procura identificar no corpus das entrevistas se há formação ou não na adoção de TIC. 'FacilAdocaoTIC' e 'DificilAdocaoTIC' busca saber se é difícil ou fácil a adoção desses recursos. 'TempoTrabalhoInfluencia' e 'TempoTrabalhoNaoInfluencia' busca agrupar os discursos que relatam se o tempo de trabalho influencia na motivação de usar os recursos tecnológicos. 'EstabilidadeInfluencia' e 'EstabilidadeNãoInfluencia' foram criadas para juntar discursos que mencionam se ter um emprego temporário ou estável influencia na utilização das TIC e recursos; 'ProblemasEstruturaFísica' e 'EstruturaFisicaAceitável', busca saber se há relatos de motivação/desmotivação de uso de TIC devido às condições da estrutura física da escola. ‘AmbienteSaudávelTrabalho' relata a coletividade e harmonização no ambiente de trabalho e o nó 'MotivacaoComNativosDigitais' relata os discursos onde os professores falam da motivação em trabalhar com adolescentes nativos digitais. Ao final de toda codificação, a ferramenta realiza análise dos dados gerando imagens que serão apresentas e discutidas posteriormente.

\section{Resultados}

\subsection{Perfil dos Entrevistados}

Foram entrevistadas 02 escolas estaduais, que ofertam o Ensino Médio, totalizando a existência de 29 professores. Desse total 11 professores foram entrevistados, 6 da primeira escola e 5 da segunda. Assim, temos uma amostra de 38\%. Para que um determinado conjunto amostral represente de maneira satisfatória o conjunto universo que ser quer medir, é necessário que ele tenha um número satisfatório de casos [Gil 2010]. Para determinação do conjunto amostral desta pesquisa foi escolhida a fórmula para o cálculo de amostras de populações finitas onde o conjunto universo não ultrapassa 100.000 indivíduos, mostrada na Figura 2, onde:

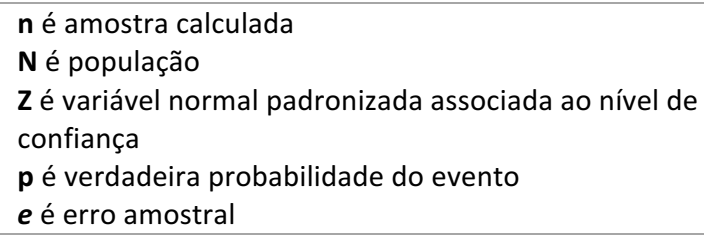

$$
n=\frac{N \cdot Z^{2} \cdot p \cdot(1-p)}{Z^{2} \cdot p \cdot(1-p)+e^{2} \cdot(N-1)}
$$

\section{Figura 2. Cálculo da amostra necessária [GIL 2010]}

Considerando um nível de confiança de $90 \%$ e um erro amostral de $20 \%$, seria necessário a participação de 11 entrevistados. É importante lembrar que o nível de confiança é a probabilidade de que o erro amostral efetivo seja menor do que o erro amostral admitido pela pesquisa. Por outro lado, o erro amostral é a diferença entre o valor estimado pela pesquisa e o verdadeiro valor [Gil 2010]. Uma observação a ser levada em consideração é que a pesquisa aqui apresentada aborda uma investigação de campo lidando com escolas públicas que possuem professores normalmente sobrecarregadas com atribuições em várias escolas, tendo horários muito restritos para atendimento, o que dificulta o acerto de dia/horário para a realização da pesquisa. Adicionalmente, os 
V Congresso Brasileiro de Informática na Educação (CBIE 2016)

Anais do XXII Workshop de Informática na Escola (WIE 2016)

professores de escolas públicas possuem uma resistência em participar de pesquisa acadêmicas por não enxergarem os benefícios de sua realização.

É importante ressaltar que todos os professores entrevistados possuem graduação em Licenciaturas específicas na sua área. Além disso, 04 deles possuem especialização em áreas diversificadas. Com relação à faixa etária e sexo, a maioria tem entre 20 e 30 anos (64\%) enquanto o restante (39\%) tem entre 50 e 60 anos. Dos professores entrevistados, a maioria é do sexo masculino (64\%). Todos eles trabalham com carga horária que varia de 16 a 32 horas semanais, tendo 08 dos entrevistados que dividem essa carga horária ensinando em outras escolas.

\subsection{Respostas às Questões de Pesquisa}

Abaixo, seguem respostas para às questões de pesquisa.

(QP01) Como são exploradas pedagogicamente as tecnologias de informação (software e hardware) nas escolas? Através da análise dos discursos é possível verificar que existe a utilização dos recursos tecnológicos (hardware e software) disponíveis na escola, porém de forma limitada, como pode ser observado no discurso de alguns entrevistados:

Entrevistado 02: "Há inserção, porém com um pouco de defasagem. Assim, não estamos 100\% funcionando. Nós temos computadores, data show, mas nem todos estão funcionando.";

Entrevistado 10: "Há, não do jeito que a gente necessita, mais há."

Observamos também que a utilização dos recursos mencionados no conjunto de perguntas acontece ou por sugestão de planejamento pedagógico ou por motivação. Fazendo uma comparação com Pirâmide da teoria de Maslow é possível observar que o fator de segurança, especificamente relacionado à permanência no trabalho principalmente para o caso dos professores temporários - é um fator que acaba sendo motivador para a adoção desses recursos tecnológicos. No entanto, há casos em que o fator motivacional de autorrealização, relacionado à diversidade e autonomia também pode ser visto quando o próprio professor toma iniciativa de usar os recursos. Isto pode se constatar nos relatados a seguir:

Entrevistado 09: "Na verdade, acho que o maior motivo é dinamizar as aulas, tornar mais atrativa em relação ao ensino aprendizagem."

Entrevistado 05: "Além do planejamento pedagógico ele tem um outro motivo, ele é estimulante, atraente, inclusive inovador."

Pode-se constatar que incentivos de ordem financeira e por competência de utilização desses recursos são inexistentes. Observou-se apenas que os incentivos surgem por parte da escola e/ou graduandos do curso de Licenciatura em Ciência da Computação (LCC) os quais estão inseridos em projetos e que por conta disso ofertam cursos de capacitação para auxiliar as escolas vinculadas, segundo consta nas seguintes falas:

Entrevistado 01: "Não, nem da instituição nem financeiro."

Entrevistado 04: "Não. Não existe nenhum incentivo, há não ser dos alunos da universidade que vem dá cursos."

Entrevistado 10: "Aqui na escola a gente é muito motivado, principalmente pela direção, secretaria."

Entrevistado 09: "No momento, não temos capacitação não."

A Figura 3 apresenta uma imagem gerada pelo NVivo que informa a similaridade dos nós através do conteúdo dos discursos inseridos em cada nó. Observando a Figura 3 é possível observar que de acordo com o discurso dos entrevistados, aqueles que participam de formação continuada acreditam que adotar TIC nas escolas é fácil, talvez porque se sentem melhor preparados para adotar as inovações tecnológicas. Por outro lado, aqueles que não possuíram nenhuma formação ou capacitação não levam em consideração o 
V Congresso Brasileiro de Informática na Educação (CBIE 2016)

Anais do XXII Workshop de Informática na Escola (WIE 2016)

impacto de ter que lidar com nativos digitais. Isso deve acontecer porque esses professores não foram capacitados para lidar com a potencialidade de melhora no processo de aprendizagem que acontece quando há inserção de tecnologia no processo de ensino a nativos digitais como é por vezes reportado na literatura.

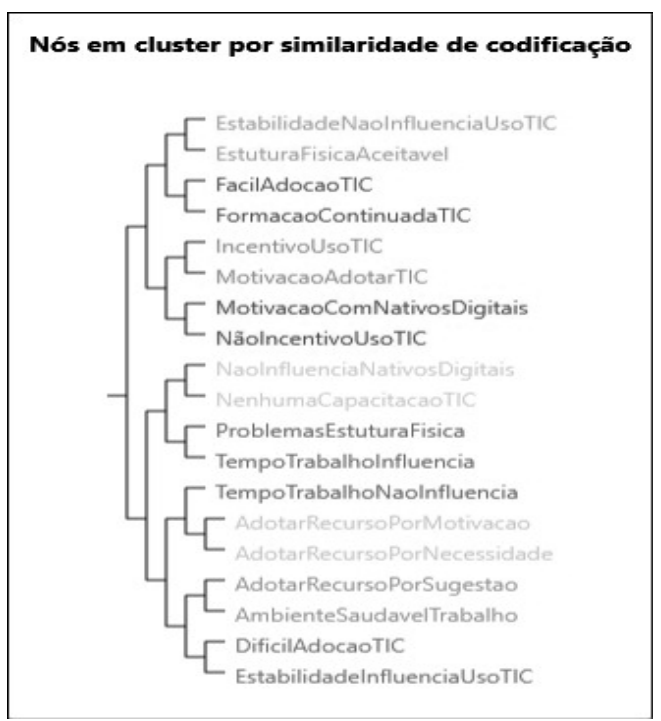

Figura 3. Análise de nós por similaridade nos discursos

Outro ponto importante que pode ser observado é que para aqueles professores que sentem que os problemas na estrutura física da escola influenciam na adoção de TIC também são os mesmos professores que acreditam que o tempo que eles trabalham durante a semana influencia na aceitação e motivação de usar TIC em suas aulas. Acredita-se que isso deve acontecer porque os professores que têm o tempo restrito e seu trabalho na escola é muito planejado e corrido, se sente menos motivado quando por exemplo, leva a turma toda para o laboratório de informática e a internet não funciona, ou quando tenta usar um software, mas ele não está instalado em todos os computadores a serem usados pelos alunos, dentre outros problemas. Ou seja, ele rejeita a possibilidade de inovar em suas aulas por ter tido alguma experiência frustrante anteriormente com a inserção desses recursos tecnológicos por falhas estruturais da escola. Isso pode ser corroborado pelo discurso de um dos entrevistados:

ENTREVISTADO 07: "Não há laboratório de informática porque não tem espaço físico para ter. E data show nós tínhamos um mas faz tempo que não vejo, que eu saiba tinha quebrado."

(2) Quais são as motivações dos professores para a utilização dos recursos tecnológicos disponíveis nas escolas? O professor na sala de aula como líder procura influenciar os seus alunos para que estes se interessem pelas aulas, estejam atentos, participem da aula, apresentem comportamentos adequados e obtenham bons resultados escolares. Um dos componentes complementares para que estas ações aconteçam é a inclusão de recursos tecnologias, observem os trechos descritos pelos entrevistados

Entrevistado 02: "A gente sempre tem que tá buscando novas ferramentas pra atrair os alunos pras aulas." Entrevistado 05: "ele é estimulante, atraente, inclusive inovador."

Entrevistado 08: "Para incrementar a aula, deixar a aula mais atrativa e fazer com que o aluno se sinta convidado a participar mais da aula.” 
V Congresso Brasileiro de Informática na Educação (CBIE 2016)

Anais do XXII Workshop de Informática na Escola (WIE 2016)

Assim, tornar a aula mais atrativa aos olhos dos alunos é um dos fatores motivadores, pois os professores buscam chamar a atenção deles para as aulas conforme relatos abaixo:

Entrevistado 02: "A gente sempre tem que tá buscando novas ferramentas pra atrair os alunos pras aulas"

Entrevistado 05: "ele é estimulante, atraente, inclusive inovador"

Entrevistado 08: "Para incrementar a aula, deixar a aula mais atrativa e fazer com que o aluno se sinta convidado a participar mais da aula."

O imediatisto de se obter e passar a informação mais atual para os alunos também é considerado outro fator motivacional, além da diversidade de fontes para pesquisa, conforme os relatos:

Entrevistado 01: “...questão de praticidade, de usarem internet, irem ao laboratório porque lá eles tem muitas informações e vão poder comparar."

Entrevistado 09: “...tem um tema que eles se interessam mais, imediatamente eles começam a pesquisar e vai aprofundando até um debate na sala de aula."

Por outro lado, o crescimento pessoal e profissional aparece nos discursos de alguns professores como sendo fatores motivacionais. Quando as tecnologias são utilizadas no dia a dia os alunos têm um posicionamento e rendimento mais satisfatório, conforme os discursos:

Entrevistado 07: "E é gratificante você ver os alunos conseguirem sair da teoria e conseguir através da pratica ver a junção e aprender melhor."

Entrevistado 06: "Os alunos gostam, como você já disse eles são nativos digitais, eles gostam de estarem mexendo nessas novas tecnologias."

Entrevistado 05: "Há crescimento pessoal, cultural e intelectual."

Por fim, aumentar de rendimento da aprendizagem dos alunos é outro fator motivador, conforme os discursos.

Entrevistado 01: "Por ser mais fácil de explicar, é muito mais fácil deles interpretarem e compreenderem."

Entrevistado 08: "se a gente traz a tecnologia pra dentro da sala de aula, a aula é proveitosa."

Entrevistado 09: "aula é mais interessante mais chamativo por parte de quem tá assistindo ou prestigiando."

Tendo como base a Teoria de Maslow (1943) sobre as necessidades humanas de trabalho, foi possível verificar uma das motivações (Crescimento Pessoal) encontradas pelos discursos dos entrevistados pode ser associada à teoria. Mesmo não seguindo a ideologia do desenvolvedor (Maslow) que afirma que quando a menor satisfação for satisfeita é possível elevar para o nível seguinte até chegar ao nível da autorrealização. No entanto, a abordagem deste trabalho focada na busca por motivações dos professores em usar TIC e não necessariamente em fatores de satisfação dos professores corroborados por esta teoria. Assim, buscou-se associar os fatores de satisfação com os fatores motivacionais assim como é proposto pelo próprio autor. E neste sentido Manfred Max (1998) afirma que as necessidades humanas fundamentais são não-hierárquicas e sim ontologicamente universais e invariáveis em sua natureza. E mais, ele indica que a pirâmide de Maslow parece ser melhor aplicável a sistemas de controle total de qualidade como foi encontrado no trabalho aqui apresentado.

(3) Se houver resistências, quais os motivos das resistências na adoção dos recursos tecnológicos disponíveis na escola? Tendo como embasamento todas as entrevistas, apenas um dos entrevistados afirmou não utilizar nenhum recurso tecnológico, nem de software nem de hardware. Este mesmo entrevistado já passou por um curso de formação e reciclagem, mas diz que não se sente valorizado pelos alunos quando se esforça para inovar em suas aulas. É possível constatar isso pelo seu discurso: 
V Congresso Brasileiro de Informática na Educação (CBIE 2016)

Anais do XXII Workshop de Informática na Escola (WIE 2016)

Entrevistado 03: "Não, o problema é que a maioria do alunado não sabe de nada, nem sei como eles chegaram até aqui, (risos). O que eu levo para a sala é só o básico."

A Figura 5 apresenta o conjunto de palavras que vêm antes e depois da palavra 'desafio' contida no corpus analisado. É possível observar através da Figura 5 que os maiores desafios e fatores desmotivantes relatados pelos professores são relacionados à estrutura física. Ela não propicia nem estimula o professor a inovar tecnologicamente em suas aulas e em alguns casos, quando o professor tentou fazer, se frustrou por algum problema de infraestrutura. Assim, fazendo um paralelo com a Teoria de Maslow, os fatores fisiológicos, relacionados ao trabalho, como conforto físico é o que mais se aproxima como sendo um fator motivador ausente nestes cenários. Os seguintes entrevistados têm discursos que corroboram essa realidade:

Entrevistado 01: "É desafiante nesse sentido de nem todos os alunos colaborar, além da escola não ter acesso adequado, às vezes tá sem internet."

Entrevistado 06: "O espaço fisicico da escola infelizmente deixa muito a desejar"

Entrevistado 04: "Os computadores aqui estão obsoletos. São computadores de memoria reduzida, a questão da internet em banda larga também é uma coisa que precisa ser colocado."

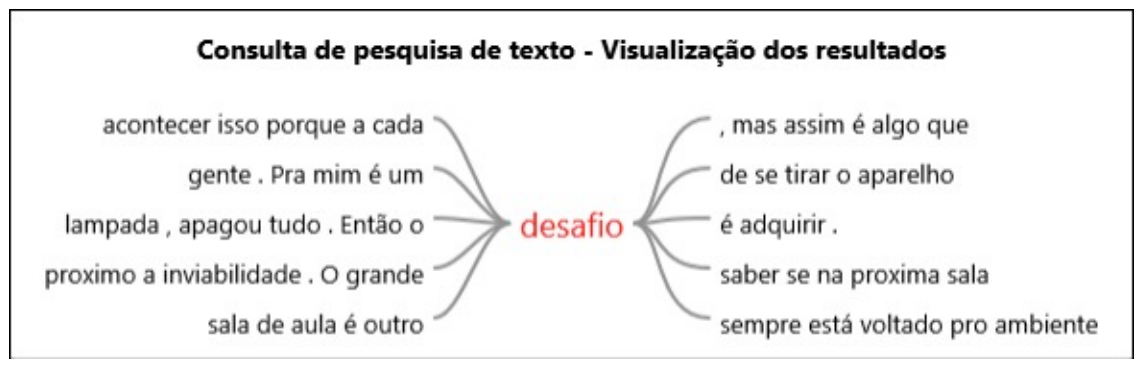

Figura 5. Consulta da palavra 'desafio'

\section{Considerações Finais}

Abastecidos dos resultados e análises descritas na seção anterior, pôde-se concluir que as duas escolas estaduais analisadas neste trabalho possuem e utilizam recursos tecnológicos (hardware e software) dentro das suas limitações de estrutura e quantidade de equipamentos disponíveis. Além disso, enfatiza-se o esforço dos professores em aderir às exigências dos superiores das escolas e buscarem a cada dia reformular suas práticas pedagógicas para atrair a atenção, o interesse e o envolvimento dos alunos nas suas aulas. Os professores mantêm-se motivados a adotar TIC, mesmo diante de vários problemas existentes nos softwares e hardwares disponíveis na escola e isso é uma das grandes causas das resistências em adotar TIC nas mesmas.

Com relação à vinculação da Teoria das Necessidades Humanas junto às análises aqui mencionadas, foi possível concluir que a realidade encontrada nas escolas não segue o ciclo proposto por Maslow, porque algumas vezes foram encontradas motivações humanas no nível de 'Estima' e “Autorrealização' (harmonização/Interação e crescimento pessoal) mesmo que as de 'Segurança' não tenha sido completamente atendidas. Apesar da importância do desenvolvimento deste trabalho para entender o processo de inserção de TIC nas escolas e a motivação dos professores em adotar ou não essas tecnologias, sugere-se como trabalho futuros: (i) investigar as utilizações tecnológicas também em escolas municipais de rede pública, (ii) analisar critérios de avaliação acerca da utilização de recursos tecnológicos, com ênfase em práticas pedagógicas bem sucedidas, (iii) realizar estudos de caso em outras escolas para checar diferentes fatores motivacionais e de 
V Congresso Brasileiro de Informática na Educação (CBIE 2016)

Anais do XXII Workshop de Informática na Escola (WIE 2016)

resistências de adoção de TIC por parte dos professores e (iv) propor soluções/alternativas para os casos de resistência em adoção à TIC.

\section{Referências}

Silva, W. B. (2014) "O uso do computador PROUCA em seis escolas do Distrito Federal”. Dissertação (mestrado) Universidade de Brasília, Faculdade de Educação. P.134.

Toschi, M. S. (2010) “A dupla mediação no processo pedagógico”. Goiânia-Goiás

Mendes, H. B. (2014) "Fatores motivacionais e sua influência no comportamento humano". Universidade do Extremo Sul de Santa Catarina - UNESC. 60 p.

Pereira, H.I.H. (2011) "Estratégias de motivação dos colaboradores nos sectores públicos e privados”. Dissertação de Mestrado- Universidade da madeira. p.89.

Filho, A.T.A (2011) “ Um mapeamento sistemático de mecanismos para guiar estudos empíricos em engenharia de software.” Dissertação de Mestrado - Universidade Federal de Pernambuco - UFPE. p.100.

Dantas, I.R., melo, D.R.M., Aquino, R.A., Silva, P.O. E Sousa, A.P. (2016) "Descrição da utilização dos recursos digitais nas escolas estaduais da 8 a região de ensino do município de Catolé do Rocha -PB" - Revista da Universidade Vale do Rio Verde, Três Corações, p. 271-278.

Fróes, I.C., Bottentuir, J.B. (2016), “Tecnologias de informação e comunicação na educação: um estudo exploratório com os alunos do ensino médio de uma escola particular em São Luís - MA"- NAMID/UFPB

Graupmann, O. (2014) "Informática e a Educação: O Paraná Digital e o processo de Informatização nas Escolas Públicas do Núcleo Regional de Educação de União da Vitória" 136 f. Dissertação (Mestrado) - Departamento de Ciências Sociais, Universidade Estadual de Maringá.

Gil, Antonio Carlos (2010), Como elaborar projetos de pesquisa. 5. ed. São Paulo: Atlas, $184 \mathrm{p}$

Maslow, A. H. A theory of human motivation. (1943) Psychological Review, 50: 390-6.

Max-Neef, Manfred. (1998) “Desarrolo a escala humana”. Barcelona: Içaria.

Ribeiro, A.V., Oliveira, C.M., Dias, D.L.M., Martins, L.O., Valim, N.C. (2015)," Teorias motivacionais" - Pontifícia Universidade Católica de Minas Gerais Campus de Poços de Caldas .

Santos, C.C.A., Ferro, E.F. (2016), “ Motivação no trabalho versus colaboradores terceirizados" - Race - Revista de administração

Santo, C.S., (2015) “Fatores motivacionais relacionados ao desempenho dos policiais do $5^{\circ}$ batalhão de polícia militar da Paraíba - monografia de especialização em gestão pública UFPB

Santos, J. D., (2015) “A (não) utilização das Tecnologias da Informação e da Comunicação pelos professores” - Artigo de revisão Literária, v. 5, n. 2, p. 21-28. Macapá. 